\title{
Design of semi-compact Z-shaped steel sheet pile walls
}

\author{
A. Enders \& U. Kuhlmann \\ Institute of Structural Design, University of Stuttgart, Stuttgart, Germany
}

\begin{abstract}
To benefit from the potentials in the bending moment capacity of semicompact Z-shaped steel sheet piles forming the infills of combined walls, four-point bending tests were carried out by the Institute of Structural Design at the Materials Testing Institute in Stuttgart in 2019. A FE-model was validated by back-calculating the tests followed by an extensive parametric study with different Z-piles. Among others the different geometries, which lead to different b/t-ratios and the steel grade were varied leading to a different compression flange slenderness. In addition, the lock state was varied to investigate the impact on the bending moment capacity as: Free lock rotation, crimped interlocks with different crimping densities and fully welded over the entire length. Three resistance models were investigated and evaluated for further development of Eurocode 3 Part 5.
\end{abstract}

\section{MOTIVATION}

Steel sheet piles are often used as infill of combined walls with H-piles as primary elements for quay walls in harbour constructions or as excavation support in civil engineering. The piles are connected with interlocks and are driven besides each other into the soil, so that they are forming a continuous wall. Among U-steel sheet piles also Z-shaped piles with free interlocks or crimped interlocks are widely used for these constructions. The sections of steel Z/U-piles and interlocks are schematically shown in Table 1.

The pressure of costs and efficiency and the competition with concrete solutions lead to necessary developments in the design of steel sheet pile walls for further economic steel solutions. New developments due to the bending moment resistance of semi-compact cross-section are included in the draft of EC-3 Part 1-1 (2020), considering elastic-plastic section modulus for the resistance of steel cross-section in buildings which are classified between cross-section class 2 and 3. To ensure consistency between the new drafts of Eurocode 3 Part 1-1 and Part 5 and to provide economical elastic-plastic resistance for Z-piles, experimental and numerical investigations were executed within the FOSTA project P1327.

\section{FOUR-POINT BENDING TESTS (4-PBT) AT THE UNIVERSITY OF STUTTGART}

The 4-PBT aimed to investigate the bending moment capacity of Z-shaped piles and the influence of crimped interlocks. In addition, a FE-Model should be validated for further numerical investigations. The test specimens were planned approximately between the $\mathrm{b} /(\mathrm{t} \cdot \varepsilon)$-ratios 45 and 66 , which are the current limits for class $2 \& 3$ and class $3 \& 4 \mathrm{Z}$-shaped cross-sections according to Eurocode 3 part 5 (2007). In sum, six 4-PBT were executed, where four double piles were with free interlocks and two were crimped. At least the double Z-piles of Test No. (3) to (6) can be defined as 'compact' and the piles of Test No. (1) and (2) are 'semi-compact'. Table 2 shows the actual elastic and plastic bending moments, which 
Table 1. U- and Z-shaped steel sheet pile sections as a single- and double-pile with interlock detail, cf. Eurocode 3 Part 5 (2007) and EN 10248 (2006).

\begin{tabular}{llll}
\hline Single Pile & Double Pile & Single Pile & Double Pile \\
\hline & & Inter-
\end{tabular}

Table 2. Tensile test results, actual resistance values in bending and cross-section classification.

\begin{tabular}{lllll}
\hline & & $\begin{array}{l}\text { actual plastic and elastic } \\
\text { bending moment in } \mathrm{kNm} \\
\mathrm{M}_{\text {act,pl }} \mid \mathrm{M}_{\text {act,el }}\end{array}$ & $\mathrm{b} /(\mathrm{t} \cdot \varepsilon)$ ratio & $\begin{array}{l}\text { class according } \\
\text { EC 3-5 }\end{array}$ \\
\hline$(1)$ & 514.8 & $1092 \mid 895$ & 56 & 3 \\
$(2)$ & 522.4 & $1247 \mid 1038$ & 49 & 3 \\
$(3)$ & 472.7 & $2830 \mid 2409$ & 40 & 2 \\
$(4)$ & 473.5 & $2830 \mid 2409$ & 40 & 2 \\
$(5)$ & 455.4 & $3510 \mid 2984$ & 33 & 2 \\
$(6)$ & 455.4 & $3450 \mid 2910$ & 33 & 2 \\
\hline
\end{tabular}

were determined with the actual geometry and yield strength, the corresponding $b /(t \cdot \varepsilon)$-ratio and the material properties. The material properties were determined with small-sample tensile tests according to ISO 6892-1 (2017). The geometry of the small tensile samples corresponded with DIN 50125-1 (2016), where the location within the section was in accordance with EN 10248 (2006).

Similar 4-PBT with industry partners were executed by Kuhlmann \& Just (2017a) with slender sheet profiles. The test setup proved to be reliable and positive experience was available, thus the general test setup was not changed. An overview of the test setup and the static system is shown in Figure 1. The test setup consisted of a frame construction made of steel (1), which was anchored in the strong floor. Two hydraulic cylinders (2) were suspended in vertical direction and attached on the horizontal beam of the frame (1). The load was introduced centered in vertical direction by the hydraulic cylinders (2) and was transferred over the distributing steel plates (4) and the H-beams (5) into the supports (6. A spherical bearing (3) was located between the hydraulic cylinder and the distributing steel plate (4) to allow rotation and avoid restraints.

The support units (9) were anchored in the strong floor. Between the support units and the test specimen (7) a sliding bearing was placed, which consisted of two Teflon layers (8) and a roller bearing. This setup allowed an almost friction-free support and a free rotation of the end plates. The distance of the supports (6) was chosen with $1.0 \mathrm{~m}$ in longitudinal direction and the distance between the support units (9) was $8.0 \mathrm{~m}$. Inclinometers $\mathbb{A}$ and displacement transducers (1) were used for the measurements between axis (B) and (C). While loading linear strain gauges recorded the strains in longitudinal direction and provided data of the stress distribution in the section. In total, 16 strain gauges per test were used, where 4 gauges were glued on the top and bottom flange and the rest of the gauges were equally distributed over the web. Rotations were measured at the endplates of the test specimen in axis (A) and (D) as well as in the middle of the double Z-pile in axis (B) and (C). The results of the experiments are shown in $\mathrm{M}-\varphi$-diagrams, see Figure 2.

The semi-compact Z-piles from the tests (1) and (2) - which are classified as class 3 sections reached bending moments, which are higher than the actual elastic bending moments. The difference between the crimped and free interlock profiles in the bending moment capacity was 


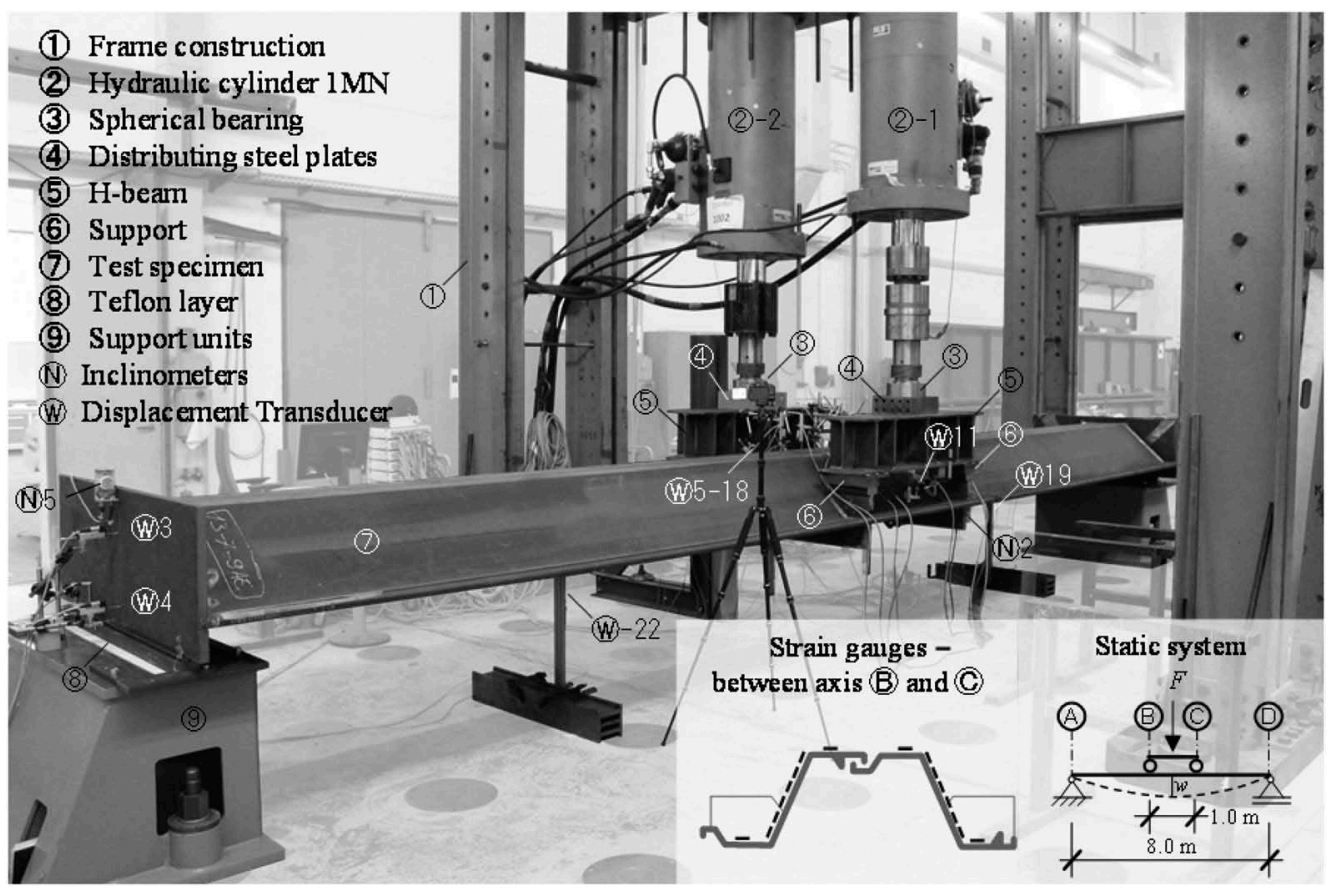

Figure 1. Test setup of the 4-PBT at the University of Stuttgart.

low, because the distance of the three crimping point repetition, which was chosen with $700 \mathrm{~mm}$, was large, cf. Figure 2 tests (3) with (4) and (5) with (6). The bending moment capacity of the tests (3) and (4) was lower than the actual plastic bending moment, though the b/ $(t \cdot \varepsilon)$-ratio was lower than 45. Similar observations were made by Kuhlmann et al. (2017a) who also confirmed that due to a movement of the locks at the compression flange downwards their contribution to the plastic moment resistance was reduced.

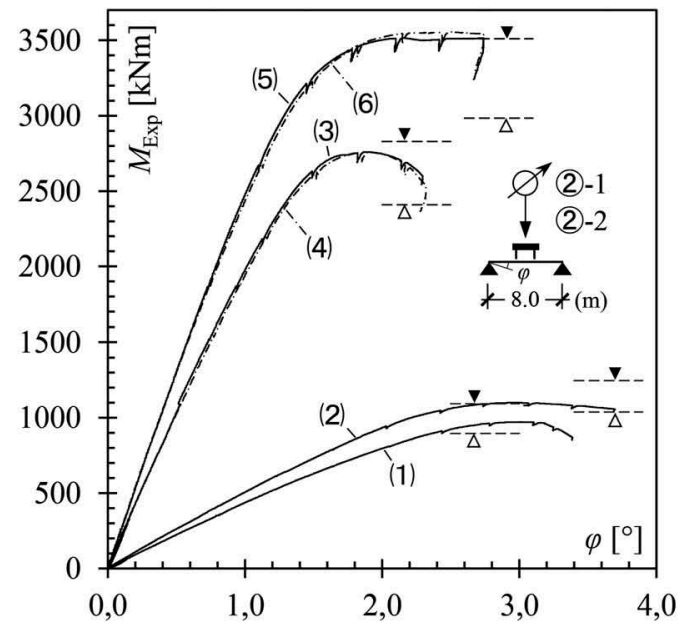

Explanations:

$$
\begin{aligned}
& M_{\text {act,pl }}-\mathbf{\nabla}_{-} \\
& M_{\text {act,el }}-\bar{\Delta}^{-\cdot} \\
& F_{\text {exp }}=\frac{F_{(2)-1}+F_{(2)-2}}{2} \\
& M_{\text {exp }}=F_{\text {exp }} \cdot 3,5 m \\
& \varphi=\frac{\varphi_{\mathbb{( N 1} 1}+\varphi_{\mathbb{N} 5}}{2}
\end{aligned}
$$

Figure 2. Results of 4-PBT: M- $\varphi$-diagram and maximum bending moment.
No. $M_{\text {exp, max }}$ in $\mathrm{kNm}$

(1)

971

(2)

1099

2760

(4)

(5)

3516

(6)

3555 


\section{BACK-CALCULATION OF THE EXPERIMENTS}

A validated FE-model was developed by Kuhlmann et al. (2017b) for an industry project. The model represents half of the test setup, as the tests were quasi-symmetric. However, this model is too time consuming for an extensive parametrical study. Thus, the existing model was improved by reducing the whole test setup to a $1.0 \mathrm{~m}$ short beam and modelling the crimping points according to Kuhlmann et al. (2021) and ArcelorMittal (2019). The FE-geometry corresponds with the measured actual geometry of the test specimen. The real stress-strain curves for the flange and web were derived from the actual stress-strain curves, which were recorded during the small sample tensile tests. The FE-model, which was built up in ANSYS is shown in Figure 3a. On the front surface, a symmetry plane in X-direction was defined. The bending moment was applied by a rotation of the stiff endplate. Solid elements were used for the Z-piles and shell elements for the stiff endplate. The contact formulation was adopted from Kuhlmann et al. (2017c) and Kuhlmann \& Enders (2019) at the interlocks. They were defined with the pure penalty method. However, a small penetration was necessary to avoid convergence issues. The calculations and experiments showed that class 2 sections in the transition zone between class 2 and 3 do not reach the plastic moment. The section is not fully plastified when the moment capacity is reached. This is a result of a shape rotation, because the locks are still not fully in contact and allow a rotation of the flange downwards. This phenomenon was also observed by Kuhlmann et al. (2017b), Just (2020) (see Figure 3b). The failure is characterised by a plastic indentation in the middle of the beam, which also happened at the experiments. The FE-results are shown in Table 3.

The mean ratio between the FE-results and the experiments is 0.99 , where minimum ratio occurred for (1) 0.97 and the maximum for (3) with a value of 1.03 . The coefficient of variation $(\mathrm{COV})$ of the ratio was $2.6 \%$. In addition, the tests were also back-calculated with the model according to Kuhlmann et al. (2017b). This led to similar results, being only slightly better: The mean ratio was 1.0 and the COV was $2.4 \%$. The reliability of the new simplified FE-model regarding the bending moment capacity is good, thus the simplified model was used for the parametric study.

a)

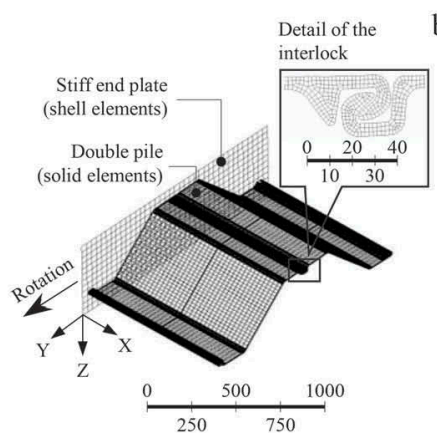

b)

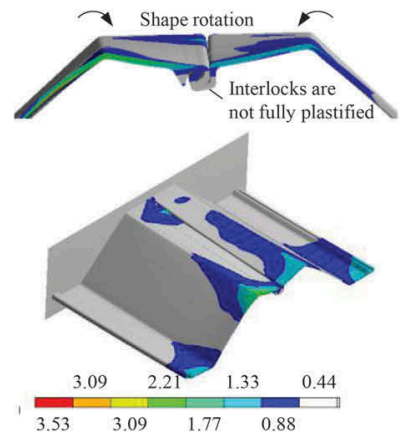

c)

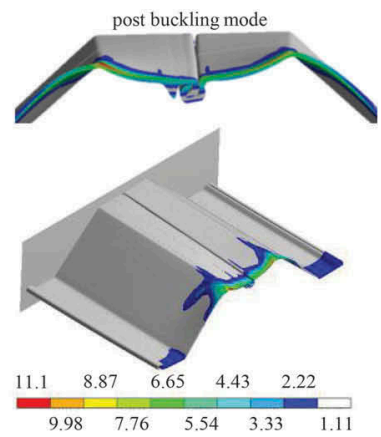

Figure 3. FE-Model exemplarily shown for test (1): a) FE-Mesh, b) strains in \% at the maximum value for the bending moment, c) strains in $\%$ at the post buckling-mode.

Table 3. Results of the test back-calculations, FE Results and Ratio between FE and Experiment.

\begin{tabular}{llllllll}
\hline Test No. & $M_{E x p, \max }$ & $M_{F E, \max }$ & Ratio & Test No. & $M_{E x p, \max }$ & $M_{F E, \max }$ & Ratio \\
\hline$(1)$ & $971 \mathrm{kNm}$ & $997 \mathrm{kNm}$ & 0.97 & $(4)$ & $2759 \mathrm{kNm}$ & $2769 \mathrm{kNm}$ & 1.00 \\
$(2)$ & $1099 \mathrm{kNm}$ & $1150 \mathrm{kNm}$ & 0.96 & $(5)$ & $3516 \mathrm{kNm}$ & $3590 \mathrm{kNm}$ & 0.98 \\
$(3)$ & $2760 \mathrm{kNm}$ & $2689 \mathrm{kNm}$ & 1.03 & $(6)$ & $3555 \mathrm{kNm}$ & $3552 \mathrm{kNm}$ & 1.01 \\
\hline
\end{tabular}


a)

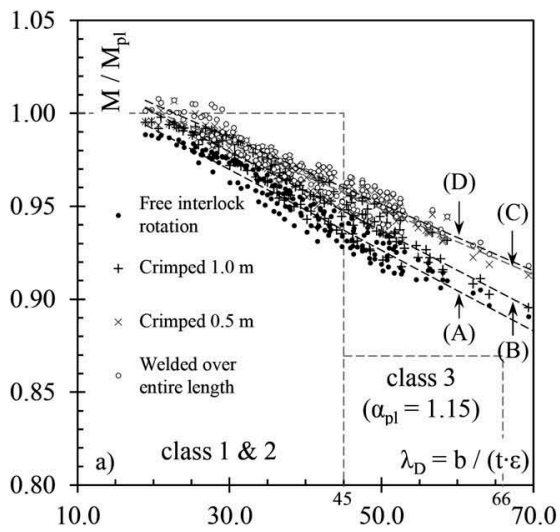

b)

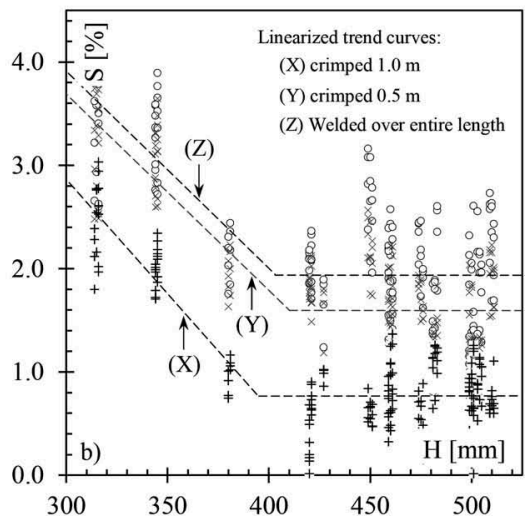

Figure 4. A) Results of the parametric study regarding the moment capacity of: Free interlocks, crimped $(0.5 \mathrm{~m})$, crimped $(1.0 \mathrm{~m})$ and welded interlocks dependent on the $\mathrm{b} /(\mathrm{t} \cdot \varepsilon)$-ratio including the trend lines (A), (B), (C), (D) for the different lock states; b) Increase S of bending moment capacity in comparison to the bending moment for free interlocks dependent on the lock state and profile height $\mathrm{H}$.

\section{PARAMETRIC STUDY}

A parametric study was carried out with the improved model to investigate the influence of the $\mathrm{b} /(\mathrm{t} \cdot \varepsilon)$-ratios and different lock states on the bending moment capacity. The lock states resulted in a different lock stiffness and were as follows: Free interlock rotation, crimped with a distance of $0.5 \mathrm{~m}$, crimped with a distance of $1.0 \mathrm{~m}$ and fully welded over the entire length. The welding seam was considered as a geometrical $6 \mathrm{~mm}$ thick one-sided fillet weld between the Z-piles. In total, 42 different profiles with nominal geometry and the steel grades S240GP, S355GP, S430GP and S460 were considered in the study. Considering all parameters 672 FE calculations were executed (Figure 4a). The experiments and the parametric study shows that Z-piles are not capable to reach the plastic moment in the transition zone at $b /(t \cdot \varepsilon)$-ratios from 30 to 45 . The crimping points with a distance of $1.0 \mathrm{~m}$ have no significant influence on the bending moment capacity, cf. Figure 4a trend curves (A) and (B). This corresponds with the tests where the distance was $0.7 \mathrm{~m}$. A crimping point distance of $0.5 \mathrm{~m}$ and the fully welded interlocks showed higher moment capacities compared to the free interlocks (Figure 4a (C) and (D)). The increase of the bending moment for crimped piles is overall low. However, for Z-piles with a height lower than $350 \mathrm{~mm}$ and a web angle lower than $43^{\circ}$, the moment increase may be of some relevance (Figure $4 \mathrm{~b}$ ).

\section{EVALUATION OF THE RESISTANCE MODELS (RM)}

The current resistance model for the bending moment capacity of Z-piles is given in Eurocode

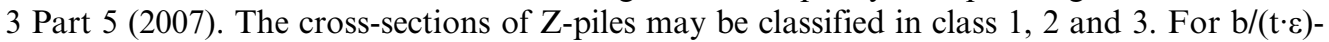
ratios up to 45 the full plastic moment may be used as the decisive value. Between the defined limits of 45 and 66, the elastic moment may be used. Following the planned procedure in the draft EC-3 Part 1-1 (2020), Annex B in sum 3 resistance models were investigated for the further development of the draft of EC-3 Part 5 (2020). It is rational to assume a linear interpolation between the defined limits, which lead to the first modified RM 'EC 3-5 (mod.)'. Hartmann-Linden (1997) suggested to use a b/(t-e)-ratio limit value of 40 between class 2 and 3 sections, which is here defined as RM 'H.-L'. Just (2020) also adopted a value 40 and modified the resistance function with a reduction factor $c$ of 0.965 for the plastic moment to consider that the plastic moment cannot be reached in the transition zone. All presented RM can 


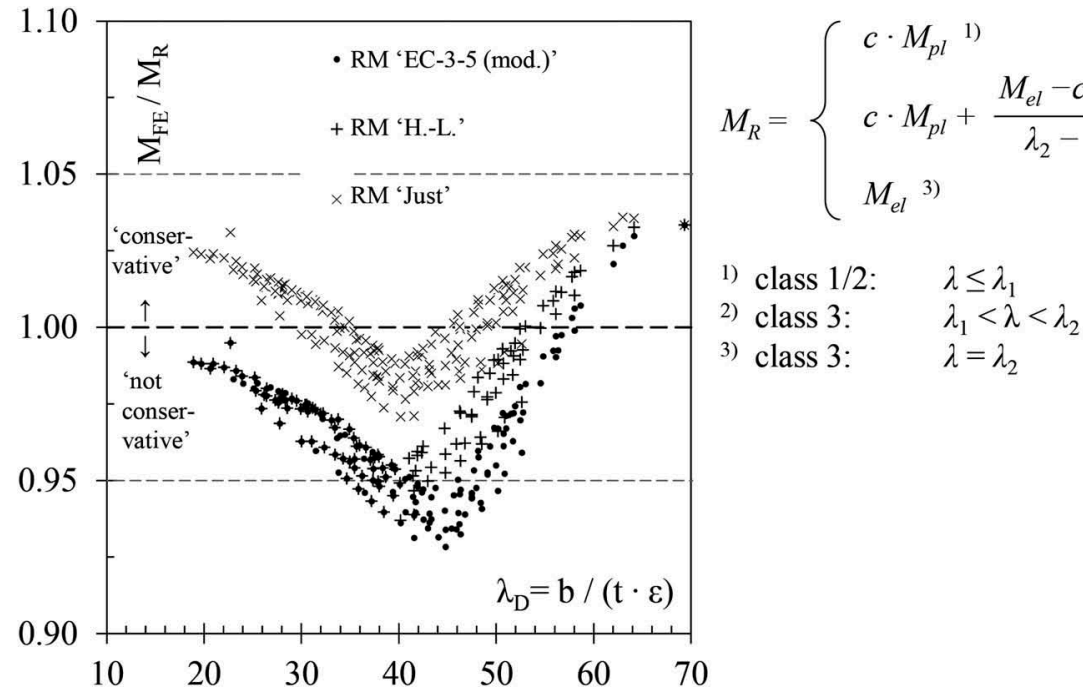

Figure 5. $\mathrm{M}_{\mathrm{FE}} / \mathrm{M}_{\mathrm{R}}$-ratios depending on the $\mathrm{RM}$ and the $\mathrm{b} /(\mathrm{t} \cdot \varepsilon)$-ratio (Kuhlmann et al (2021)).

be described with the following resistance function, shown in Eq. (1). The Factor $c$ in Eq. (1) is a constant factor, which reduces the plastic bending moment; $\lambda_{1}$ is the limit between class 2 and 3 sections; $\lambda_{2}$ is the limit between class 3 and 4 and $\lambda$ is defined as the $\mathrm{b} /(\mathrm{t} \cdot \varepsilon)$-ratio, where $\varepsilon$ is a material-dependent value and is defined by $\left(235 / f_{\mathrm{y}}\right)^{0.5}$ (see Eurocode 3 Part $5(2007)$ ). The bending moment capacity of the parametric study with the validated model was compared with the resistance models (see Figure 5). $\mathrm{M}_{\mathrm{FE}} / \mathrm{M}_{\mathrm{R}}$-ratios above 1.0 indicate a 'conservative' and ratios below a 'not conservative' resistance model. In addition, the resistance models were evaluated within the FOSTA Project P1327 following the standardized procedure in Eurocode 0 (2010) Annex D to derive partial factors.

\section{CONCLUSION}

Four-point bending tests were carried out with Z-shaped steel sheet piles to investigate the bending moment capacity. A FE-model was developed to execute an extensive parametric study with different nominal geometries, steel grades and interlock states. The crimping of Z-piles may be considered for profiles with a height lower than $350 \mathrm{~mm}$ and a web angle lower than $43^{\circ}$. Then, three resistance models for semi-compact sections following the draft of EC-3 Part 1-1 (2020) and in respect of Just (2020) and Hartmann-Linden (1997) were tested and evaluated according to Eurocode 0 (2010) Annex D. The results serve for a further discussion in the working group TC250/SC3/WG 18 and a further development of the draft of EC-3 Part 5 (2020) regarding the consideration of semi-compact cross-section in bending of Z-shaped steel sheet piles.

\section{ACKNOWLEDGMENTS}

The work presented has been carried out as part of the FOSTA research project P1327 financed by $\mathrm{AiF}$, within the development program for industrial community research and development IGF from the Federal Ministry of Economic Affairs and Energy based on a decision of the German Bundestag. Special thanks to ArcelorMittal S.A. Luxembourg for their support by materials and fabrication of the test specimens. We would also like to thank the industrial committee accompanying the project for technical and practical support and 
our project partners Prof. Dr. J. Grabe and J. Beuße, M.Sc. from Technical University of Hamburg-Harburg for their good cooperation.

\section{REFERENCES}

ArcelorMittal. 2019. Behaviour of AZ crimping. Background document. Unpublished.

DIN 50125. 2016. DIN 50125: 2016-12:Testing of metallic materials - Tensile test pieces. In German.

EN 10248. 2006. EN 10248-1: 2006-05:Hot-rolled steel sheet piling, Part 1: Technical delivery conditions.

Eurocode 0. 2002. EN 1990: 2010-12: Eurocode: Basis of structural design.

Eurocode 3 Part 5. 2007. EN 1993-5:2007: Eurocode 3: Design of steel structures - Part 5: Piling.

Hartmann-Linden. 1997. Tragfähigkeit von Stahlspundwänden. Dissertation, University of Aachen, Institute of Steel Construction.

ISO 6892-1. 2017. EN ISO 6892-1: 2017-02: Metallic materials - Tensile testing - Part 1: Method of test at room temperature.

Just A. 2020. Zum Tragverhalten von Stahlspundwänden mit breiten Zwischenbohlen. Dissertation, University of Stuttgart, Institute of Structural Design.

Kuhlmann, U.; Enders A. 2019. Investigations on combined sheet pile walls (HZ/AZ System) under water pressure loading, Experimental investigations with five AZ | HZ combinations in reverse setup position (b), 4th Addition to the Experimental Report 2010-24X. Experimental Report, University of Stuttgart, Institute of Structural Design, No. 2019-8X. Unpublished.

Kuhlmann, U.; Grabe, J.; Beuße, J.; Enders, A. 2021. Optimized Design of Combined Steel Walls for the Installation Phase and the Final State. Final Report of the AiF-FOSTA-Project P 1327 (IGF No. 19937 N), Düsseldorf. In progress.

Kuhlmann, U.; Just A. 2017a. Test Report AZXL: 800 mm wide AZ sheet piles, Phase 3: Three and FourPoint Bending Tests. Technical report, University of Stuttgart, Institute of Structural Design, No. 2017-2X. Unpublished.

Kuhlmann, U.; Just A. 2017b. Expert Statement AZXL: $800 \mathrm{~mm}$ wide AZ sheet piles, Phases 2 and 3 Load-Deformation Behavior: Bending and Waling. Final Report, No. 2017-64X, University of Stuttgart, Institute of Structural Design, 2017. Unpublished.

Kuhlmann, U.; Just A. 2017c. Combined HZ-MIAZ Pile Walls Loaded with Water Pressure, Evaluation of Additional Tests and Statistical Re-evaluation of the Characteristic Resistance Values. Final Report, Expert Statement, No. 2017-56X, University of Stuttgart, Institute of Structural Design. Unpublished.

Draft EC-3 Part 1-1. 2020. prEN 1993-1-1:2020: Eurocode 3 - Design of steel structures - Part 1-1: General rules and rules for buildings, document TC250/SC3/N3159.

Draft EC-3 Part 5. 2020. prEN 1993-5:2020: Eurocode 3: Design of steel structures - Part 5: Piling, document TC250/SC3/N3200. 